\title{
Optimum Combination of Femoral Head Size, Femoral Head Material, and Acetabular Cup Liner's Highly-Cross-Linked Polyethylene Brand for Hip Implant
}

\author{
Gladius Lewis*, Daniel M. Werdofa \\ Department of Mechanical Engineering, The University of Memphis, Memphis, USA \\ Email: "glewis@memphis.edu
}

Received 19 December 2014; accepted 6 January 2015; published 16 January 2015

Copyright (C) 2015 by authors and Scientific Research Publishing Inc.

This work is licensed under the Creative Commons Attribution International License (CC BY).

http://creativecommons.org/licenses/by/4.0/

(c) (i) Open Access

\begin{abstract}
Clinical two-dimensional linear wear rate data for acetabular cup liners fabricated using approved brands of highly cross-linked ultra-high-molecular-weight polyethylene, as reported in 39 articles in the literature, were analyzed using a statistical technique called response surface methodology. The output was a series comprising16 acceptable combinations of femoral head diameter (HD), femoral head material (HM), and HXLPE brand (PB), each of which would yield the optimum wear rate (herein taken to be a wear rate of practically zero). An example of such a combination is 28mm-diameter Oxinium ${ }^{\circledR}$ femoral head articulated against an acetabular cup liner fabricated from Reflection $^{\mathrm{TM}}$ HXLPE. The findings in this work may guide an orthopaedic surgeon's selection of the combination of HD, HM, and PB to use in a primary total hip joint replacement.
\end{abstract}

\section{Keywords}

Highly-Cross-Linked Ultra-High Molecular-Weight Polyethylene, Acetabular Cup Liner, Linear Wear

\section{Introduction}

In recognition of the detrimental role that ultra-high-molecular-weight polyethylene (UHMWPE) wear particles

${ }^{*}$ Corresponding author.

How to cite this paper: Lewis, G. and Werdofa, D.M. (2015) Optimum Combination of Femoral Head Size, Femoral Head Material, and Acetabular Cup Liner's Highly-Cross-Linked Polyethylene Brand for Hip Implant. J. Biomedical Science and Engineering, 8, 31-39. http://dx.doi.org/10.4236/ibise.2015.81003 
play in osteolysis in total joint replacements (TJRs), research and development attention, over the past 30 or so years, has focused on methods to reduce the wear of UHMWPE in counter-surfaces in TJRs. The state-of-the-art involves highly cross-linking the UHMWPE using radiation. There are two variants. The first involves gamma irradiating the fabricated polymer component at, typically, between $65 \mathrm{kGy}$ and $100 \mathrm{kGy}$. The free radicals, which are produced by the breakage of the $\mathrm{C}-\mathrm{H}$ bonds in the polymer, react with each other to form cross-links between adjacent molecule chains. The residual free radicals (that is, those that remain after the cross-linking) are completely quenched or reduced substantially with the aid of a thermal stabilization treatment, namely, annealing (heating the polymer to about or below $135^{\circ} \mathrm{C}$, which is its melt temperature) or remelting (heating to a temperature $>135^{\circ} \mathrm{C}$ ) [1]. In the second variant, the fabricated polymer component is exposed to electron beam radiation at, typically, between $65 \mathrm{kGy}$ and $100 \mathrm{kGy}$. The method used for thermal stabilization of the residual free radicals is, usually, remelting [1]. There are a number of commercial HXLPE brands that belong to one of the two aforementioned variants and which are approved, by the appropriate regulatory bodies (such as the US Food and Drug Administration), for fabricating bearing surfaces for TJRs. Currently, the predominant use is for acetabular cup liners in primary total hip joint replacements (THJRs) [1].

There is a very large body of literature on two-dimensional 2D clinical wear rate of HXLPE acetabular cup liners in primary THJRs and the influence of three important variables (femoral head size (HD), femoral head material (HM), and HXPLE brand (PB)) on this rate [2]-[47] (Table 1). There is, however, no guidance on the optimum combination of the aforementioned variables. The purpose of the present study was to provide such guidance. This was done through using 2D linear wear rate results, given in 39 literature reports, and an optimization computation carried out with the aid of a technique called response surface methodology (RSM) [48].

\section{Data and Method of Analysis}

Femoral head 2D linear penetration rate (the accepted proxy for linear wear) results for HXLPE acetabular cup liners given in 39 peer-reviewed articles published in archival journals were collected. To do this, a detailed computerized search was conducted of relevant databases (such as MEDLINE ${ }^{\circledR} /$ PubMed and PubMed Central) and the table of contents of relevant journals (such as Acta Orthopaedica, Archives of Orthopedic Trauma and Surgery, Clinical Orthopaedics and Related Research, European Journal of Orthopaedic Surgery and Traumatology, Journal of Bone and Joint Surgery-American edition, The Bone \& Joint Journal (formerly known as Journal of Bone and Joint Surgery-British edition), The Journal of Arthroplasty, and Seminars in Arthroplasty) for articles published, through September 2014, in English as well as in other languages (provided English translations were available). The keywords used were: HXLPE, HXLPE wear, femoral head penetration, total hip arthroplasty, THJR, and TJR. In addition, the list of references in each article found in the search was manually examined in order to identify additional relevant and acceptable articles. (Conference abstracts and presentations were not regarded as "acceptable" articles because they were not published in peer-review archival journals.) Through this process, a final total of 39 articles that contained all the details on clinical wear of HXLPE acetabular cup liners relevant to our study, namely, HD, HM, PB, method of 2D linear wear determination, and steady-phase linear wear rate result was obtained. The steady-phase linear wear rate results, taken from these articles (Table 1), were used in the RSM work.

Design-of-experiments (DOE) is a statistical method that is used to determine the optimum conditions for a process that involves many independent variables with the minimum of experimental replications. One widely used DOE method is called response surface methodology (RSM). In RSM, a response variable may be expressed using a second-order polynomial (regression) model; in other words, the equation (model) is given by

$$
\text { Response variable }=\mathrm{b}_{\mathrm{o}}+\sum \mathrm{b}_{\mathrm{i}} \mathrm{X}_{\mathrm{i}}+\sum \mathrm{b}_{\mathrm{ii}} \mathrm{X}_{\mathrm{i}}^{2}+\sum \mathrm{b}_{\mathrm{ij}} \mathrm{X}_{\mathrm{i}} \mathrm{X}_{\mathrm{j}}+\varepsilon \text {, }
$$

where $X_{i}$ and $X_{j}$ are raw values of the factors (independent/explanatory variables), $b_{0}$ is the constant coefficient, $b_{i}$ is the coefficients of the linear parameters, $b_{i i}$ is the coefficients of the quadratic parameters, $b_{i j}$ is the coefficient of the interaction parameters, and $\varepsilon$ represents the error in the observed value of the variable.

Two common outputs from a RSM analysis are 1) analysis of variance (determination of the adequacy of the developed model and the statistical significance of the regression coefficients in Equation (1) and their influence on the response variable); and 2) combination of values of the explanatory variables that yield the optimum value of the dependent variable. In the present work, attention was limited to optimization of the response variable, namely, 2D steady-phase linear wear rate (WR). 
Table 1. Summary of salient features of the dataset on clinical two-dimensional mean steady-phase linear wear rate of highly cross-linked UHMWPE Acetabular liners.

\begin{tabular}{|c|c|c|c|c|}
\hline Head Diameter (mm) & Head Material & HXLPE Brand & Mean Wear Rate (mm/year) & Source \\
\hline 28 & Co-Cr (3) & Crossfire (2) & 0.12 & Martell et al. [2] \\
\hline 28 & Co-Cr (3) & Marathon (6) & 0.08 & Hopper et al. [3] \\
\hline 28 & Co-Cr (3) & Crossfire (2) & 0.05 & Krushell et al. [4] \\
\hline 28 & Co-Cr (3) & Crossfire (2) & 0.036 & D’Antonio et al. [5] \\
\hline 28 & Co-Cr (3) & Longevity (5) & 0.018 & Manning et al. [6] \\
\hline 28 & Co-Cr (3) & Durasul (3) & 0.010 & Manning et al. [6] \\
\hline 28 & Co-Cr (3) & Durasul (3) & 0.029 & Dorr et al. [7] \\
\hline 28 & Co-Cr (3) & Marathon (6) & 0.010 & Engh et al. [8] \\
\hline 32 & Co-Cr (3) & Durasul (3) & 0.010 & Bragdon et al. [9] \\
\hline 28 & $\mathrm{Al}_{2} \mathrm{O}_{3}(1)$ & Aeonian (1) & 0.006 & Oonishi et al. [10] \\
\hline 28 & Co-Cr (3) & Marathon (6) & 0.010 & Leung et al. [12] \\
\hline 28 & Co-Cr (3) & Crossfire (2) & 0.006 & Rohrl et al. [13] \\
\hline 28 & Co-Cr (3) & Durasul (3) & 0.025 & Triclot et al. [14] \\
\hline 28 & Co-Cr (3) & Longevity (5) & 0.050 & Olyslaegers et al. [15] \\
\hline 28 & Co-Cr (3) & Longevity (5) & 0.030 & Glynn-Jones et al. [16] \\
\hline 28 & Co-Cr (3) & Marathon (6) & 0.031 & Bitsch et al. [17] \\
\hline 28 & Oxinium (4) & Longevity (5) & 0.004 & Garvin et al. [18] \\
\hline 28 & Co-Cr (3) & Crossfire (2) & 0.022 & Rajadhyaksa et al. [19] \\
\hline 28 & Co-Cr (3) & Marathon (6) & 0.0239 & Calvert et al. [20] \\
\hline 28 & $\mathrm{Al}_{2} \mathrm{O}_{3}(1)$ & Marathon (6) & 0.060 & Kim et al. [21] \\
\hline 28 & Co-Cr (3) & Duration (4) & 0.088 & Geerdink et al. [22] \\
\hline 22.225 & $\mathrm{ZrO}_{2}(6)$ & Aeonian (1) & 0.067 & Ise et al. [24] \\
\hline 22.225 & Stainless Steel (5) & Aeonian (1) & 0.068 & Ise et al. [24] \\
\hline 26 & Co-Cr (3) & Aeonian (1) & 0.010 & Kawate et al. [25] \\
\hline 26 & $\mathrm{ZrO}_{2}(6)$ & Aeonian (1) & 0.000 & Kawate et al. [25] \\
\hline 28 & Co-Cr (3) & Longevity (5) & 0.028 & Lachiewicz et al. [28] \\
\hline 28 & Co-Cr (3) & Marathon (6) & 0.007 & Campbell et al. [29] \\
\hline 26 & $\mathrm{ZrO}_{2}(6)$ & Longevity (5) & 0.010 & Fukui et al. [30] \\
\hline 28 & Co-Cr (3) & Reflection (7) & 0.026 & Whittaker et al. [31] \\
\hline 28 & Co-Cr (3) & Longevity (5) & 0.025 & Whittaker et al. [31] \\
\hline 44 & Co-Cr (3) & Durasul (3) & 0.021 & Hammerberg et al. [32] \\
\hline 26 & Co-Cr (3) & Longevity (5) & $<0.001$ & Nakahara et al. [33] \\
\hline 26 & $\mathrm{ZrO}_{2}(6)$ & Longevity (5) & $<0.001$ & Nakahara et al. [33] \\
\hline 28 & Co-Cr (3) & Marathon (6) & 0.050 & Mutimer et al. [35] \\
\hline
\end{tabular}




\begin{tabular}{|c|c|c|c|c|}
\hline \multicolumn{5}{|l|}{ Continued } \\
\hline 36 & Biolox (2) & X3 (8) & 0.022 & Meftah et al. [36] \\
\hline 36 & Biolox (2) & X3 (8) & 0.052 & Meftah et al. [36] \\
\hline 28 & Co-Cr (3) & Crossfire (2) & 0.031 & Capello et al. [38] \\
\hline 28 & Co-Cr (3) & Crossfire (2) & 0.002 & Rohrl et al. [39] \\
\hline 28 & Co-Cr (3) & Crossfire (2) & 0.014 & Ranawat et al. [40] \\
\hline 28 & Co-Cr (3) & Crossfire (2) & 0.043 & Ranawat et al. [40] \\
\hline 28 & Co-Cr (3) & Crossfire (2) & 0.011 & Ranawat et al. [40] \\
\hline 28 & Co-Cr (3) & Crossfire (2) & 0.038 & Ranawat et al. [40] \\
\hline 28 & Co-Cr (3) & Durasul (3) & 0.005 & Johanson et al. [41] \\
\hline 28 & Co-Cr (3) & Durasul (3) & 0.010 & Bragdon et al. [42] \\
\hline 28 & Co-Cr (3) & Marathon (6) & 0.014 & Callary et al. [44] \\
\hline 28 & $\mathrm{Al}_{2} \mathrm{O}_{3}(1)$ & Marathon (6) & 0.031 & Kim et al. [45] \\
\hline 26 & $\mathrm{ZrO}_{2}(6)$ & Longevity (5) & 0.045 & Fukui et al. [46] \\
\hline 32 & Co-Cr (3) & X3 (8) & $<0.001$ & Callary et al. [47] \\
\hline
\end{tabular}

Head material numeric identifiers are as follows: 1 : $\mathrm{Al}_{2} \mathrm{O}_{3} ; 2$ : $\mathrm{Biolox}^{\circledR}$ (a commercially-available zirconia-toughened platelet-reinforced alumina); 3: Co-Cr; 4: Oxinium ${ }^{\circledR}$ (commercially-available oxidized $\mathrm{Zr}$ alloy); 5: Stainless steel; 6: $\mathrm{ZrO}_{2}$ (generic). HXLPE brand numeric identifies are as follows: 1: Aeonian ${ }^{\mathrm{TM}}$ (Kyocera Corp., Kyoto, Japan); 2: Crossfire $^{\circledR}$ (Stryker Orthopaedics, Mahwah, NJ); 3: Durasul ${ }^{\circledR}$ (Zimmer, Warsaw, IN); 4: Duration ${ }^{\circledR}$ (Stryker Orthopaedics); 5: Longevity ${ }^{\circledR}$ (Zimmer); 6: Marathon $^{\circledR}$ (DePuy, Warsaw, IN); 7: Reflection ${ }^{\mathrm{TM}}$ (Smith \& Nephew, Memphis, TN); 8: X3 ${ }^{\mathrm{TM}}$ (Stryker Orthopaedics).

The dataset (Table 1) contains one quantitative explanatory variable (HD), two non-quantitative or categorical explanatory variables (HM and PB), and a quantitative response variable (WR). This meant utilizing a special type of RSM, called the D-optimal fraction method. The first step in this utilization was to assign numerical identifiers for HM and for PB. The next step was to insert these identifiers into the dataset (Table 1) and then to specify that the optimum WR is when WR is practically zero. The optimization was performed utilizing a commercially-available DOE software package (Design Expert ${ }^{\circledR}$, Version 8; Stat-Ease, Inc., Minneapolis, MN, USA).

\section{Results}

For each combination of HD, HM, and PB, the software package computed, using settings specified by the user, a relative importance score for each variable and then combined these scores into a single number, called the desirability index, which ranged from zero (minimum desirability) to 1 (maximum desirability). 24 combinations, each with a desirability index of least 0.999999 , were obtained. These combinations, together with the associated computed linear wear rates, are given in Table 2.

\section{Discussion}

Although there were 24 combinations of femoral head size, femoral head material, and HXLPE brand that yield a HXPLE liner 2D linear wear rate of practically zero, in making a selection of a combination to use, other issues should be considered. One such issue is the reported surface degradation of zirconia femoral heads over time in vivo ( $>5$ years) associated with phase transformation of the ceramic [49]. Thus, in Table 2, all combinations involving a zirconia femoral head were removed, leaving 16 acceptable combinations.

The study has a number of limitations. The first comprises issues with the studies from which the dataset (Table 1) was derived (hereafter, referred to as the "surveyed studies"). One of these issues is that large femoral heads (HD $\geq 36 \mathrm{~mm}$ ) were used in only a few of the surveyed studies. The consensus is that, in a primary THJR, when a large femoral head is used instead of one with $\mathrm{HD}<36 \mathrm{~mm}$, the dislocation rate is significantly lower although other measures, such as implant survivorship clinical outcomes (for example, incidence of loosening 
Table 2. Summary of two computed features of combinations of femoral head size, femoral head material, and Acetabular cup liner HXLPE brand with desirability $>0.99999$.

\begin{tabular}{|c|c|c|c|c|}
\hline Head Diameter (mm) & $\begin{array}{c}\text { Head Material } \\
\text { Numeric Identifier }\end{array}$ & $\begin{array}{l}\text { HXLPE Brand } \\
\text { Numeric Identifier }\end{array}$ & $\begin{array}{l}\text { Computed Mean Wear } \\
\text { Rate (mm/year) }\end{array}$ & $\begin{array}{c}\text { Computed } \\
\text { Desirability Index }\end{array}$ \\
\hline 25.31 & 4 & 3 & $1.58 \times 10^{-9}$ & 0.99999999 \\
\hline 26.47 & 4 & 1 & $2.64 \times 10^{-9}$ & 0.99999998 \\
\hline 25.72 & 3 & 1 & $6.66 \times 10^{-9}$ & 0.99999994 \\
\hline 30.89 & 5 & 8 & $9.70 \times 10^{-9}$ & 0.99999992 \\
\hline 27.28 & 1 & 3 & $2.08 \times 10^{-8}$ & 0.99999983 \\
\hline 28.96 & 4 & 7 & $3.37 \times 10^{-8}$ & 0.999999972 \\
\hline 27.18 & 1 & 7 & $3.93 \times 10^{-8}$ & 0.99999967 \\
\hline 26.26 & 6 & 3 & $4.67 \times 10^{-8}$ & 0.99999961 \\
\hline 27.14 & 1 & 6 & $5.26 \times 10^{-8}$ & 0.99999956 \\
\hline 26.87 & 1 & 1 & $5.70 \times 10^{-8}$ & 0.99999953 \\
\hline 26.99 & 1 & 2 & $6.72 \times 10^{-8}$ & 0.99999944 \\
\hline 23.97 & 4 & 8 & $7.16 \times 10^{-8}$ & 0.99999940 \\
\hline 36.96 & 2 & 8 & $7.25 \times 10^{-8}$ & 0.99999940 \\
\hline 31.98 & 1 & 8 & $7.49 \times 10^{-8}$ & 0.99999938 \\
\hline 27.08 & 1 & 5 & $7.68 \times 10^{-8}$ & 0.99999936 \\
\hline 26.00 & 6 & 1 & $8.64 \times 10^{-8}$ & 0.99999928 \\
\hline 25.99 & 1 & 4 & $1.00 \times 10^{-7}$ & 0.99999914 \\
\hline 26.39 & 6 & 5 & $1.19 \times 10^{-7}$ & 0.99999901 \\
\hline 26.33 & 6 & 6 & $1.19 \times 10^{-7}$ & 0.99999901 \\
\hline 27.49 & 6 & 4 & $2.71 \times 10^{-7}$ & 0.99999774 \\
\hline 26.49 & 6 & 2 & $3.13 \times 10^{-7}$ & 0.999999739 \\
\hline 24.80 & 3 & 8 & $3.73 \times 10^{-7}$ & 0.99999689 \\
\hline 26.29 & 6 & 7 & $5.90 \times 10^{-7}$ & 0.99999508 \\
\hline 25.42 & 6 & 8 & $8.33 \times 10^{-7}$ & 0.99999306 \\
\hline
\end{tabular}

and migration of acetabular components), radiographic results (for example, subsidence of acetabular components), functional outcomes (for example, Harris hip score and UCLA activity score), and complications (for example, wound drainage and atrial fibrillation), are similar [50] [51]. The second issue is that among the surveyed studies there were differences in many important variables, such as patient age, patient weight, acetabular cup design, number of surgeons, implantation technique, and method of anchorage of the acetabular cup to the contiguous bone (Table 3). The third issue is that although, in each of the surveyed studies, anteroposterior and/or lateral radiographs of the pelvis were taken, an assortment of methods were used to determine 2D linear wear rates, such as the computer-assisted edge-detection method introduced by Martell et al. [4] [6] [11] [12] [14] [17] [19] [20] [28] [31] [35] [37] [42], radiostereometry [13] [16] [29] [39] [41] [44], a dedicated computer software package [21] [22] [24] [30] [40] [43] [45], utilization of a manual method based on the Microsoft Power Point software package [23], and the concentric circle method introduced by Livermore et al. [36] [38]. The literature on comparison of methods of determination of clinical 2D linear wear rate utilizing measurements made on HXLPE acetabular cup liners, in a specified patient set, is very limited [23] [40]. However, it is worth noting 
Table 3. Comparison of some study features in selected literature clinical reports.

\begin{tabular}{|c|c|c|c|c|c|c|}
\hline Study Feature & Martell et al. [2] & Dorr et al. [7] & Triclot et al. [14] & $\begin{array}{l}\text { Lachiewicz } \\
\text { et al. [28] }\end{array}$ & Capello et al. [38] & Kim et al. [45] \\
\hline Patient age (yr) & $60.0(28-76.0)$ & $60.2 \pm 16.2$ & $70.6(44-85)$ & $61.1(27-87)$ & $55.8 \pm 10.0$ & $28.3(21$ - 29) \\
\hline $\begin{array}{l}\text { Patient bodymass } \\
\text { index }\left(\mathrm{kg} / \mathrm{m}^{2}\right)\end{array}$ & $30.6(18.1-48.0)$ & NS & $26.2(17.6$ - 39.6) & $29.0(18.9$ - 46.4) & $27.4 \pm 4.5$ & $25.0(22.4-27.2)$ \\
\hline $\begin{array}{l}\text { Number of } \\
\text { surgeons }\end{array}$ & $>1$ & 1 & 1 & 1 & 1 & 1 \\
\hline $\begin{array}{l}\text { Acetabular cup } \\
\text { design and fixation } \\
\text { method }\end{array}$ & $\begin{array}{l}\text { Secur-Fit HA } \\
\text { (Stryker); }\end{array}$ & NS & $\begin{array}{c}\text { Fitmore } \\
\text { (Zimmer); } \\
\text { uncemented }\end{array}$ & $\begin{array}{l}\text { Trilogy (Zimmer); } \\
\text { uncemented }\end{array}$ & $\begin{array}{l}\text { Secur-Fit HA } \\
\text { PSL (Stryker); } \\
\text { uncemented }\end{array}$ & $\begin{array}{l}\text { Duraloc 100/1200 } \\
\text { (DePuy); } \\
\text { uncemented }\end{array}$ \\
\hline $\begin{array}{l}\text { Femoral stem } \\
\text { design and } \\
\text { fixation method }\end{array}$ & $\begin{array}{l}\text { Secur-Fit or } \\
\text { Secur-FitPlus } \\
\text { HA (Stryker)/ } \\
\text { cementedor } \\
\text { uncemented }\end{array}$ & $\begin{array}{l}\text { Anatomic Porous } \\
\text { Replacement } \\
\text { (Zimmer)/ } \\
\text { uncemented; Apollo } \\
\text { (Zimmer) cemented; } \\
\text { Anatomic Medullary } \\
\text { Locking (DePuy) }\end{array}$ & $\begin{array}{l}\text { Emeraude } \\
\text { (Zimmer) }\end{array}$ & NS & $\begin{array}{l}\text { Omnifit HA } \\
\text { (Stryker); } \\
\text { uncemented }\end{array}$ & $\begin{array}{c}\text { Immediate } \\
\text { Postoperative } \\
\text { Stability (DePuy); } \\
\text { uncemented }\end{array}$ \\
\hline Follow-up (yr) & 2 & “at least 5” & $4.9(4.2-6.1)$ & $5.7(5-8)$ & $8.6(7.0-10.3)$ & $10.8(10-12)$ \\
\hline $\begin{array}{l}\text { Number of hips } \\
\text { available } \\
\text { for analysis at latest } \\
\text { follow-up }\end{array}$ & 36 & 37 & 49 & 102 & 42 & 60 \\
\hline
\end{tabular}

NS: Information not stated in report. Patient age given as mean with range in parentheses.

that comparable wear rates were found when determinations were made using either two manual methods (PowerPoint versus Livermore; Longevity; $28 \mathrm{~mm}$ Co-Cr femoral head) [23] or two computer-assisted methods (Martell versus Livermore with Roman software; Crossfire; 28 mm Co-Cr femoral head; mean follow-up of 5.7 yr) [40].

The second limitation is that although in the majority of the reports of the surveyed studies, it was explicitly stated that the 2D linear rate was corrected for deformation without attendant wear (principally, creep) suffered during the bedding-in period, in other reports, this was not the case [3] [14] [23] [40] [45]. Furthermore, in cases in which it was explicitly stated that correction for bedding-in was done, there was variation in the duration considered as the length of the bedding-in period, examples being 2 months [13], 6 months [20], 1 year [5], and 2 years [19] post-implantation.

Since results from the surveyed studies were utilized, none of the matters discussed in the above-mentioned two limitations could be circumvented because these matters are intrinsic features of these studies. In fact, the only way to avoid these issues is to conduct prospective clinical studies specifically designed with the study purpose in the present work in mind; that is, hold all variables, except for HD, HM, and PB, constant.

The third limitation is that the analysis was of reported 2D linear wear rates, rather than three-dimensional (3D) volumetric wear rates. This was because 2D linear wear rate is the commonly used parameter; thus, of the 39 articles used in the analysis, 3D volumetric wear was reported in only 14 of them (30\%) [2] [8] [10] [12] [14] [17] [20] [24] [25] [28] [32] [35] [42] [46]. In the determination of the wear rate of HXLPE acetabular cup liners, there is very little discussion, in the literature, of the relative attractions and shortcomings of 2D linear versus 3D volumetric methods, for the same patient set, except to note that the latter method has higher accuracy but lower precision compared to the former one [52].

One of the challenges in using RSM is to demonstrate that the parameter estimation in the equation used (in the present study, Equation (1)) is robust. This is especially germane in a case, such as in the present work, in which the initial independent/explanatory variables dataset is a mixture of qualitative parameters (head material and HXLPE brand) and a quantitative parameter (head diameter). One manifestation of this challenge is that, in the results, a phenomenon known as "aliased matrix" is encountered, which is where, in the computation, some rows of data are skipped. The fourth study limitation is that we assumed that the RSM design used was robust [53]. 


\section{Conclusion}

From a statistical analysis of clinical 2D linear wear rates of HXLPE acetabular cup liners in primary total hip joint replacements, reported in 39 literature studies, 24 combinations of femoral head diameter, femoral head material, and HXLPE brand that would lead to the optimum wear rate (herein, taken to be a rate of practically zero) were found. However, given widespread concerns about in vivo surface degradation of zirconia femoral heads, all combinations involving this type of head were removed from further consideration, leaving 16 combinations that are deemed acceptable. An example acceptable combination is $28 \mathrm{~mm}$ diameter Oxinium ${ }^{\circledR}$ femoral head articulated against a Reflection ${ }^{\mathrm{TM}}$ HLXPE acetabular cup liner.

\section{References}

[1] Kurtz, S.M., Gawel, H.A. and Patel, J.D. (2011) History and Systematic of Wear and Osteolysis Outcomes for FirstGeneration Highly Crosslinked Polyethylene. Clinical Orthopaedics and Related Research, 469, 2262-2277. http://dx.doi.org/10.1007/s11999-011-1872-4

[2] Martell, J.M., Verner, J.J. and Incavo, S.J. (2003) Clinical Performance of a Highly Cross-Linked Polyethylene at Two Years in Total Hip Arthroplasty: A Randomized Prospective Trial. The Journal of Arthroplasty, 18, 55-59. http://dx.doi.org/10.1016/S0883-5403(03)00341-3

[3] Hopper, R.H., Young, A.M., Orishimo, K.F. and McAuley, J.P. (2003) Correlation between Early and Late Wear Rates in Total Hip Arthroplasty with Application to the Performance of Marathon Cross-Linked Polyethylene Liners. The Journal of Arthroplasty, 18, 60-67. http://dx.doi.org/10.1016/S0883-5403(03)00294-8

[4] Krushell, R.J., Fingeroth, R.J. and Cushing, M.C. (2005) Early Femoral Head Penetration of a Highly Cross-Linked Polyethylene Liner vs a Conventional Polyethylene Liner. The Journal of Arthroplasty, 20, 73-76. http://dx.doi.org/10.1016/j.arth.2005.05.008

[5] D’Antonio, J.A., Manley, M.T., Capello, W.N., Bierbaum, B.E., Ramakrishnan, R., Naughton, M. and Sulton, K. (2005) Five-Year Experience with Crossfire Highly Cross-Linked Polyethylene. Clinical Orthopaedics and Related Research, 441, 143-150. http://dx.doi.org/10.1097/00003086-200512000-00024

[6] Manning, D.W., Chiang, P.P., Martell, J.M., Galante, J.O. and Harris, W.H. (2005) In Vivo Comparative Wear Study of Traditional and Highly Cross-Linked Polyethylene in Total Hip Arthroplasty. The Journal of Arthroplasty, 20, 880-886. http://dx.doi.org/10.1016/j.arth.2005.03.033

[7] Dorr, L.D., Wan, Z., Shahrdar, C., Sirianni, L., Boutary, M. and Yun, A. (2005) Clinical Performance and a Durasul Highly Cross-Linked Polyethylene Acetabular Liner for Total Hip Arthroplasty at Five Years. Journal of Bone and Joint Surgery, 87-A, 1816-1821.

[8] Engh Jr., C.A., Stepniewski, A.S., Ginn, S.D., Beykirch, S.E., Sychterz-Terefenko, C.J., Hopper, R.H. and Engh, C.A. (2006) A Randomized Prospective Evaluation of Outcomes after Total Hip Arthroplasty Sing Cross-Linked Marathon and Non-Cross-Linked Enduron Polyethylene Liners. The Journal of Arthroplasty, 21, 17-25. http://dx.doi.org/10.1016/j.arth.2006.05.002

[9] Bradgon, C.R., Barrett, S., Martell, J.M., Greene, M.E., Malchau, H. and Harris, W.H. (2006) Steady-State Penetration Rates of Electron Beam-Irradiated, Highly Cross-Linked Polyethylene at an Average 45-Month Follow-Up. The Journal of Arthroplasty, 21, 935-943.

[10] Oonishi, H., Kim, S.C., Takao, Y., Kyomoto, M., Iwamoto, M. and Ueno, M. (2006) Wear of Highly Cross-Linked Polyethylene Acetabular Cup in Japan. The Journal of Arthroplasty, 21, 944-949. http://dx.doi.org/10.1016/j.arth.2006.03.009

[11] Bragdon, C.R., Kwan, Y.M., Geller, J.A., Greene, M.E., Freiberg, A.A., Harris, W.H. and Malchau, H. (2007) Minimum 6-Year Follow-Up of Highly Cross-Linked Polyethylene in THA. Clinical Orthopaedics and Related Research, 465, 122-127.

[12] Leung, S.B., Egawa, H., Stepnieswski, A., Beykirch, S., Engh, C.A. and Engh, C.A. (2007) Incidence and Volume of Pelvic Osteolysis at Early Follow-Up with Highly Cross-Linked and Noncross-Linked Polyethylene. Journal of Arthroplasty, 22, 134-139. http://dx.doi.org/10.1016/j.arth.2007.04.006

[13] Rohrl, S.M., Li, M.G., Nilsson, K.G. and Nivbrant, B. (2007) Very Low Wear of Non-Remelted Highly Cross-Linked Polyethylene Cups: An RSA Study Lasting up to 6 Years. Acta Orthopaedica, 78, 739-745. http://dx.doi.org/10.1080/17453670710014509

[14] Triclot, P., Grosjean, G., Masri, F.E., Courpied, J.P. and Hamadouche, M. (2007) A Comparison of Penetration Rate of Two Polyethylene Acetabular Liners of Different Levels of Cross-Linked: A Prospective Randomized Trial. Journal of Bone and Joint Surgery-British Volume, 89-B, 1439-1445. http://dx.doi.org/10.1302/0301-620X.89B11.19543

[15] Olyslaegers, C., Defoort, K., Simon, J.P. and Vandenberghe, L. (2008) Wear in Conventional and Highly Cross-Linked Polyethylene Cups: A 5-Year Follow-Up Study. Journal of Arthroplasty, 23, 489-494. 
http://dx.doi.org/10.1016/j.arth.2007.02.013

[16] Glyn-Jones, S., Smith, P.M., Gill, H.S. and Murray, D.W. (2008) The Creep and Wear of Highly Cross-Linked Polyethylene: A Three-Year Randomized, Controlled Trial Using Radiostereometric Analysis. Journal of Bone and Joint Surgery-British Volume, 90-B, 556-561. http://dx.doi.org/10.1302/0301-620X.90B5.20545

[17] Bitsch, R.G., Loidolt, T., Heisel, C., Ball, S. and Schmalzried, T.P. (2008) Reduction of Osteolysis with Use of Marathon Cross-Linked Polyethylene: A Concise Follow-Up, at a Minimum of Five Years, of a Previous Report. Journal of Bone and Joint Surgery (American), 90, 1487-1491. http://dx.doi.org/10.2106/JBJS.F.00991

[18] Garvin, K.L., Hartman, C.W., Mangla, J., Murdoch, N. and Martell, J.M. (2009) Wear Analysis in THA Utilizing Zirconium and Cross-Linked Polyethylene. Clinical Orthopaedics and Related Research, 467, 141-145. http://dx.doi.org/10.1007/s11999-008-0544-5

[19] Rajadhyaksha, A.M., Brotea, C., Cheung, Y., Kuhn, C., Ramakrishnan, R. and Zelicof, S.B. (2009) Five-Year Comparative Study of Highly Cross-Linked (Crossfire) and Traditional Polyethylene. Journal of Arthroplasty, 24, 161-167. http://dx.doi.org/10.1016/j.arth.2007.09.015

[20] Calvert, G.T., Devane, P.A., Fielden, J., Adams, K. and Horne, J.G. (2009) A Double-Blind, Prospective, Randomized Controlled Trial Comparing Highly Cross-Linked and Conventional Polyethylene in Primary Total Hip Arthroplasty. Journal of Arthroplasty, 24, 505-510. http://dx.doi.org/10.1016/j.arth.2008.02.011

[21] Kim, Y.H., Kim, J.S., Choi, Y.W. and Kwon, O.R. (2009) Intermediate Results of Simultaneous Alumina-on-Alumina Bearing and Alumina-on-Highly Cross-Linked Polyethylene Bearing Total Hip Arthroplasties. Journal of Arthroplasty, 24, 885-891. http://dx.doi.org/10.1016/j.arth.2008.05.009

[22] Geerdink, C.H., Grimm, B., Vencken, W., Heyligers, I.C. and Tonino, A.J. (2009) Cross-Linked Compared with Historical Polyethylene in THA: An 8-Year Clinical Study. Clinical Orthopaedics and Related Research, 467, 979-984. http://dx.doi.org/10.1007/s11999-008-0628-2

[23] Yun, H.H., Jajodia, N.K., Myung, J.S., Oh, J.K., Park, S.W. and Shon, W.Y. (2009) Use of Slide Presentation Software as a Tool to Measure Hip Arthroplasty Wear. Journal of Arthroplasty, 24, 1210-1215. http://dx.doi.org/10.1016/j.arth.2009.06.012

[24] Ise, K., Kawanabe, K., Tamura, J., Akiyama, H., Goto, K. and Nakamura, T. (2009) Clinical Results of the Wear Performance of Cross-Linked Polyethylene in Total Hip Arthroplasty, Prospective Randomized Trial. Journal of Arthroplasty, 24, 1216-1220. http://dx.doi.org/10.1016/j.arth.2009.05.020

[25] Kawate, K., Ohmura, T., Kawahara, I., Tamai, K., Ueha, T. and Takemura, K. (2009) Differences in Highly CrossLinked Polyethylene Wear between Zirconia and Cobalt-Chromium Femoral Heads in Japanese Patients. Journal of Arthroplasty, 24, 1221-1224. http://dx.doi.org/10.1016/j.arth.2009.05.023

[26] Beksac, B., Salas, A., Della Valle, A.G. and Salvati, E.A. (2009) Wear in Reduced in THA Performed with Highly Cross-Linked Polyethylene. Clinical Orthopaedics and Related Research, 467, 1765-1772. http://dx.doi.org/10.1007/s11999-008-0661-1

[27] Shia, D.S., Clohisy, J.C., Schinsky, M.F., Martell, J.M. and Maloney, W.J. (2009) THA with Highly Cross-Linked Polyethylene in Patients 50 Years or Younger. Clinical Orthopaedics and Related Research, 467, 2059-2065. http://dx.doi.org/10.1007/s11999-008-0697-2

[28] Lachiewicz, P.F., Heckman, D.S., Soileau, E.S., Mangla, J. and Martell, J.M. (2009) Femoral Head Size and Wear of Highly Cross-Linked Polyethylene at 5 to 8 Years. Clinical Orthopaedics and Related Research, 467, 3290-3296. http://dx.doi.org/10.1007/s11999-009-1038-9

[29] Campbell, D., Mercer, G., Nilson, K.G., Wells, V., Field, J.R. and Callary, S.A. (2010) Wear of a Highly Cross-Linked Polyethylene Liner: A Preliminary RSA Study. European Journal of Orthopaedic Surgery \& Traumatology, 20, $23-27$. http://dx.doi.org/10.1007/s00590-009-0486-y

[30] Fukui, K., Kaneuji, A., Sugimori, T., Ichiseki, T., Kitamura, K. and Matsumoto, T. (2011) Wear Comparison between a Highly Cross-Linked Polyethylene and Conventional Polyethylene against a Zirconia Femoral Head: Minimum 5-Year Follow-Up. Journal of Arthroplasty, 26, 45-49. http://dx.doi.org/10.1016/j.arth.2009.11.005

[31] Whittaker, J.P., Charron, K.D., McCalden, R.W., MacDonald, S.J. and Bourne, R.B. (2010) Comparison of Steady State Femoral Head Penetration Rates between Two Highly Cross-Linked Polyethylenes in Total Hip Arthroplasty. Journal of Arthroplasty, 25, 680-686. http://dx.doi.org/10.1016/j.arth.2009.05.006

[32] Hammerberg, E.M., Wan, Z., Dastane, M. and Dorr, L.D. (2010) Wear and Range of Motion of Different Femoral Head Sizes. Journal of Arthroplasty, 25, 839-843. http://dx.doi.org/10.1016/j.arth.2009.07.007

[33] Nakahara, I., Nakamura, N., Nishii, T., Miki, H., Sakai, T. and Sugano, N. (2010) Minimum Five-Year Follow-Up Wear Measurement of Longevity Highly Cross-Linked Polyethylene Cup against Cobalt-Chromium or Zirconia Heads. Journal of Arthroplasty, 25, 1182-1187. http://dx.doi.org/10.1016/j.arth.2009.09.006

[34] Campbell, D., Field, J.R. and Callary, S.A. (2010) Second-Generation Highly Cross-Linked X3 Polyethylene Wear: A 
Preliminary Radiostereometric Analysis Study. Clinical Orthopaedics and Related Research, 468, 2704-2709. http://dx.doi.org/10.1007/s11999-010-1259-y

[35] Mutimer, J., Devane, P.A., Adams, K. and Horne, J.G. (2010) Highly Crosslinked Polyethylene Reduces Wear in Total Hip Arthroplasty at 5 Years. Clinical Orthopaedics and Related Research, 468, 3228-3233. http://dx.doi.org/10.1007/s11999-010-1379-4

[36] Meftah, M., Ebrahimpour, B., He, C., Rabawat, A.S. and Ranawat, C.S. (2011) Short-Term Analysis and Clinical Performance of Large Ceramic Heads on Highly Cross-Linked Polyethylene in Young and Active Patients. Seminars in Arthroplasty, 22, 225-228. http://dx.doi.org/10.1053/j.sart.2011.09.002

[37] Mall, N.A., Nunley, R.M., Zhu, J.J., Maloney, W.J., Barrack, R.L. and Clohisy, J.C. (2011) The Incidence of Acetabular Osteolysis in Young Patients with Conventional versus Highly Crosslinked Polyethylene. Clinical Orthopaedics and Related Research, 469, 372-381. http://dx.doi.org/10.1007/s11999-010-1518-y

[38] Capello, W.N., D’Antonio, J.A., Ramakrishnan, R. and Naughton, M. (2011) Continued Improved Wear with an Annealed Highly Cross-Linked Polyethylene. Clinical Orthopaedics and Related Research, 469, 825-830. http://dx.doi.org/10.1007/s11999-010-1556-5

[39] Rohrl, S.M., Nivbrant, B. and Nilsson, K.G. (2012) No Adverse Effects of Submelt-Annealed Highly Crosslinked Polyethylene in Cemented Cups. An RSA Study of 8 Patients 10 Years after Surgery. Acta Orthopaedica, 83, 148-152. http://dx.doi.org/10.3109/17453674.2011.652889

[40] Ranawat, A.S., Tsallis, P., Meftah, M., Koob, T.W., Rodriguez, J.A. and Ranawat, C.S. (2012) Minimum 5-Year Wear Analysis of First-Generation Highly Cross-Linked Polyethylene in Patients 65 Years and Younger. Journal of Arthroplasty, 27, 354-357. http://dx.doi.org/10.1016/j.arth.2011.07.003

[41] Johanson, P.E., Digas, G., Herberts, P., Thanner, J. and Karrholm, J. (2012) Highly Crosslinked Polyethylene Does Not Reduce Aseptic Loosening in Cemented THA 10-Year Findings of a Randomized Study. Clinical Orthopaedics and Related Research, 470, 3083-3093. http://dx.doi.org/10.1007/s11999-012-2400-x

[42] Bradgon, C.R., Doerner, M., Martell, J., Jarrett, B., Palm, H. and Malchau, H., Multicenter Study Group (2013) The 2012 John Charnley Award: Clinical Multicenter Studies of the Wear Performance of Highly Crosslinked Remelted Polyethylene in THA. Clinical Orthopaedics and Related Research, 471, 393-402. http://dx.doi.org/10.1007/s11999-012-2604-0

[43] Babovic, N. and Trousdale, R.T. (2013) Total Hip Arthroplasty Using Highly Cross-Linked Polyethylene in Patients Younger than 50 Years with Minimum 10-Year Follow-Up. Journal of Arthroplasty, 28, 815-817. http://dx.doi.org/10.1016/j.arth.2012.12.005

[44] Callary, S.A., Campbell, D.G., Mercer, G., Nilsson, K.G. and Field, J.R. (2013) Wear of a 5 Megarad Cross-Linked Polyethylene Liner: A 6-Year RSA Study. Clinical Orthopaedics and Related Research, 471, 2238-2244. http://dx.doi.org/10.1007/s11999-013-2789-X

[45] Kim, Y.H., Park, J.W., Patel, C. and Kim, D.Y. (2013) Polyethylene Wear and Osteolysis after Cementless Total Hip Arthroplasty with Alumina-on-Highly Cross-Linked Polyethylene Bearings in Patients Younger than Thirty Years of Age. Journal of Bone and Joint Surgery (American), 95, 1088-1093. http://dx.doi.org/10.2106/JBJS.L.01211

[46] Fukui, K., Kaneuji, A., Sugimori, T., Ichiseki, T. and Matsumoto, T. (2013) Wear Comparison between Conventional and Highly Cross-Linked Polyethylene against a Zirconia Head: A Concise Follow-Up, at an Average 10 Years, of a Previous Report. Journal of Arthroplasty, 28, 1654-1658. http://dx.doi.org/10.1016/j.arth.2012.12.020

[47] Callary, S.A., Field, F.R. and Campbell, D.G. (2013) Long Wear of a Second-Generation Highly Crosslinked Polyethylene Liner: A 5-Year Radiostereometric Analysis Study. Clinical Orthopaedics and Related Research, 471, 35963600. http://dx.doi.org/10.1007/s11999-013-3188-z

[48] Myers, R.H. (2008) RSM: Process and Product Optimization Using Designed Experiments. John Wiley \& Sons, Inc, New York.

[49] Haraguchi, K., Sugano, N., Nishii, T., Miki, H., Oka, K. and Yoshikawa, H. (2001) Phase Transformation of a Zirconia Ceramic Head after Total Hip Arthroplasty. Journal of Bone and Joint Surgery, 83-B, 996-1000. http://dx.doi.org/10.1302/0301-620X.83B7.12122

[50] Stroh, D.A., Issa, K., Johnson, A.J., Delanois, R.E. and Mont, M.A. (2013) Reduced Dislocation Rates and Excellent Functional Outcomes with Large-Diameter Femoral Heads. Journal of Arthroplasty, 28, 1415-1420. http://dx.doi.org/10.1016/j.arth.2012.11.017

[51] Allen, C.L., Hooper, G.J. and Frampton, C.M.A. (2014) Do Larger Femoral Heads Improve the Functional Outcome in Total Hip Arthroplasty? Journal of Arthroplasty, 29, 401-404. http://dx.doi.org/10.1016/j.arth.2013.06.017

[52] Martell, J.M., Berkson, E., Berger, R. and Jacobs, J. (2003) Comparison of Two- and Three-Dimensional Computerized Polyethylene Wear Analysis after Total Hip Arthroplasty. Journal of Bone and Joint Surgery, 85-A, 1111-1117.

[53] Aggarwal, M.L. and Bansal, A. (1998) Robust Response Surface Designs for Qualitative and Quantitative Factors. Communications in Statistics-Theory and Methods, 27, 89-106. http://dx.doi.org/10.1080/03610929808832652 
Scientific Research Publishing (SCIRP) is one of the largest Open Access journal publishers. It is currently publishing more than 200 open access, online, peer-reviewed journals covering a wide range of academic disciplines. SCIRP serves the worldwide academic communities and contributes to the progress and application of science with its publication.

Other selected journals from SCIRP are listed as below. Submit your manuscript to us via either submit@scirp.org or Online Submission Portal.
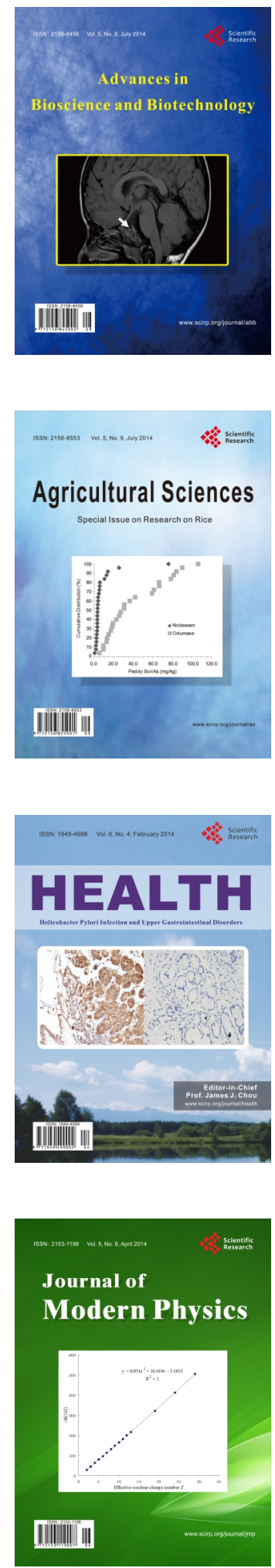
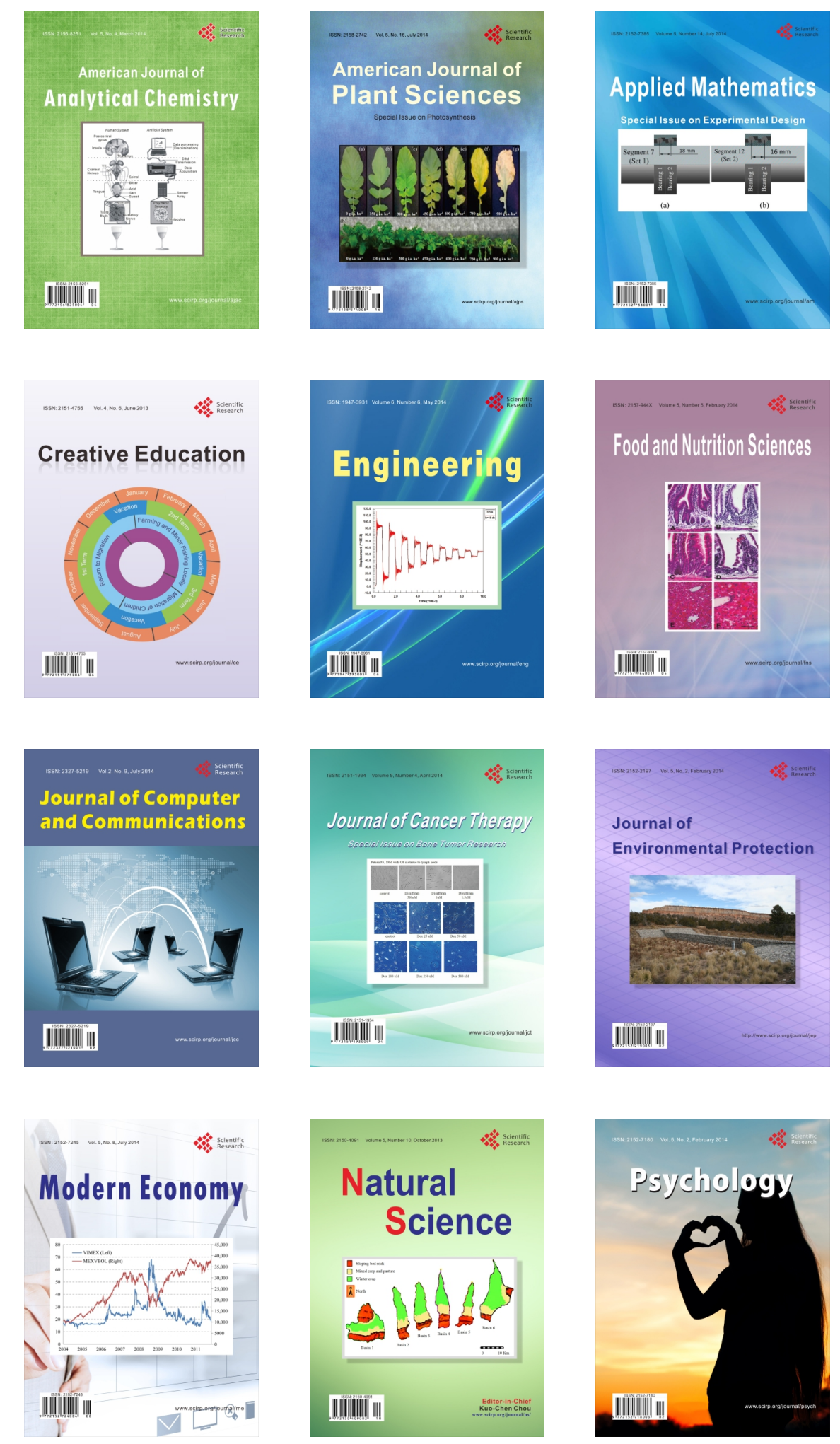